\title{
PEG cross-linked Chitosan: a biomacromolecule as corrosion inhibitor for sugar industry
}

\author{
D. S. Chauhan ${ }^{1}$-V. Srivastava ${ }^{2} \cdot$ P. G. Joshi ${ }^{2} \cdot$ M. A. Quraishi ${ }^{1}$
}

Received: 17 April 2018 / Accepted: 18 December 2018 / Published online: 29 December 2018

(c) The Author(s) 2018

\begin{abstract}
The present work reports the application of polyethylene glycol (PEG) cross-linked chitosan (Cht-PEG) as a green corrosion inhibitor. This is the first study reporting the application of Cht-PEG as corrosion inhibitor for mild steel in $1 \mathrm{M}$ sulphamic acid solution. The results of gravimetric measurements, electrochemical study and surface analysis (SEM) are presented in this work. The adsorption of the inhibitor over the mild steel surface obeyed the Langmuir isotherm. At an optimum concentration of $200 \mathrm{ppm}$, the maximum corrosion inhibition efficiency obtained was $93.9 \%$. The electrochemical impedance spectroscopy (EIS) study showed an increase in polarization resistance with increase in the concentration of inhibitor justifying the adsorption and inhibition behaviour. Potentiodynamic polarization indicated that the Cht-PEG behaved as a mixed type inhibitor with cathodic predominance. The density functional theory (DFT) based calculations supported the experimental observations.
\end{abstract}

\section{Graphical Abstract}

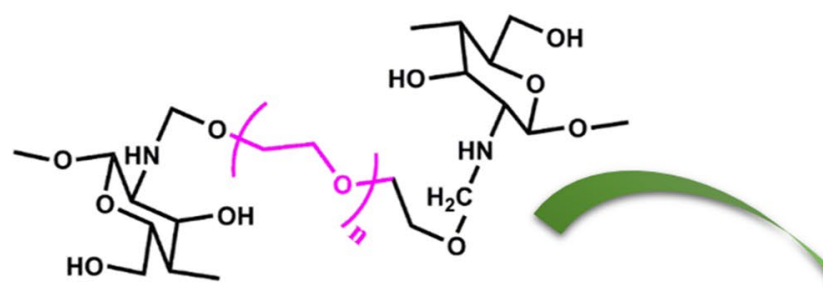

Chitosan-PEG

\section{Mild Steel}
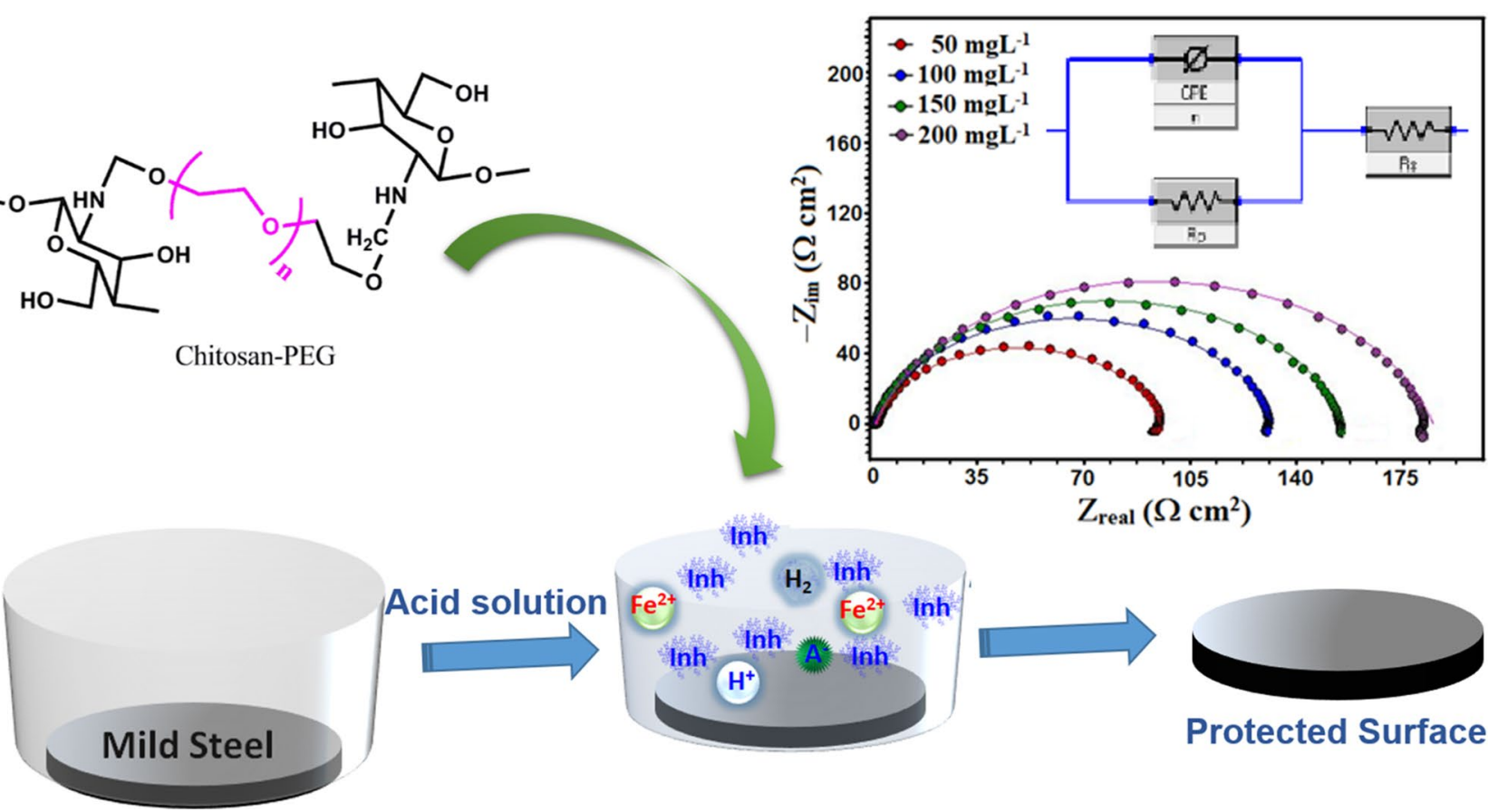

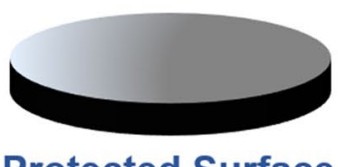

Protected Surface

Electronic supplementary material The online version of this article (https://doi.org/10.1007/s40090-018-0165-0) contains supplementary material, which is available to authorized users.

Extended author information available on the last page of the article 
Keywords Chitosan $\cdot$ Biomacromolecule $\cdot$ Corrosion inhibition $\cdot$ Potentiodynamic polarization $\cdot$ Electrochemical impedance spectroscopy $\cdot$ Density functional theory

\section{Introduction}

Sulphamic acid $\left(\mathrm{H}_{2} \mathrm{NSO}_{3} \mathrm{H}\right)$, is used as a cleaning agent in industrial equipment and for the removal of process scales in sugar industry. Sulphamic acid can be used on mild steel and stainless steel without causing pitting or chloride-induced stress corrosion cracking (SCC) [1-3]. The aqueous solutions of sulphamic acid do not emit corrosive fumes but solubilize scales with its $-\mathrm{NH}_{2}$ and $-\mathrm{OH}$ functional groups thereby forming soluble compounds with most industrial deposits [3-8]. Addition of a corrosion inhibitor to sulphamic acid solution is very important to keep the surface of metal intact and reduce the damage due to corrosion during the cleaning and pickling process. However, most of the synthetic corrosion inhibitors are harmful to the environment, which has directed the attention of scientists on the development of non-toxic green corrosion inhibitors $[9,10]$.

In this context, the high molecular weight organic polymeric molecules such as carboxymethyl cellulose, Gum Arabic, Tapioca Starch, Chitosan (Cht) and polyethylene glycol (PEG) etc. have been reported as efficient corrosion inhibitors [9-18]. In addition, the PEG cross-linked chitosan hydrogels have been reported for protein and drug release, tissue adhesives and immunotherapy. The introduction of PEG chains to the chitosan matrix improves the solubility and bioavailability of the chitosan-PEG (Cht-PEG) [19-21]. Earlier we have carried out a study on chitosan and its synergism with KI for corrosion inhibition of mild steel in $1 \mathrm{M}$ sulphamic acid and inhibition efficiencies of $73.8 \%$ and $90.3 \%$ respectively were obtained at $200 \mathrm{mg} \mathrm{L}^{-1}$ concentration [15]. We have also reported the application of thiosemicarbazide and thiocarbohydrazide modified chitosan and Schiff bases of chitosan as corrosion inhibitors for mild steel in $1 \mathrm{M} \mathrm{HCl}[22,23]$. The high efficiency of chemically modified chitosan [24] prompted us to explore the anticorrosion property of PEG modified chitosan.
In the continuation of our work on chitosan based corrosion inhibitors, we herein for the first time, report PEG cross-linked chitosan (Cht-PEG) as a novel eco-friendly corrosion inhibitor for mild steel in $1 \mathrm{M}$ sulphamic acid solution. This modification can improve the solubility and molecular weight of the inhibitor leading to enhanced inhibition behaviour. The study was performed using weight loss method, electrochemical measurements, surface morphology and quantum chemical investigation. The corrosion inhibition property was investigated using gravimetric and electrochemical measurements and surface characterization. Theoretical calculations were carried out to corroborate the experimental results.

\section{Experimental}

\section{Materials and inhibitor synthesis}

Polyethylene glycol (PEG; MW 4000) was obtained from SD fine chemicals, Mumbai. Formaldehyde $(37 \% \mathrm{w} / \mathrm{w})$ and formic acid $98-100 \%$ were procured from HiMedia, India. All the other chemicals used were of analytical grade and were obtained from Merck India Ltd. Chitosan (MW 50,000 to 190,000 Da; 75-85\% deacytelated) was obtained from Aldrich, USA.

The synthesis of PEG cross-linked chitosan (Cht-PEG) was carried out using formaldehyde as reported earlier [25]. Chitosan ( $1 \mathrm{~g}$ ) was dissolved in $10 \mathrm{~mL}$ formic acid to obtain a viscous solution followed by the addition of $1 \mathrm{~g}$ PEG. After stirring for $15 \mathrm{~min}, 1 \mathrm{~mL}$ formaldehyde was added and the solution was mixed thoroughly for $60 \mathrm{~min}$. The resulting Cht-PEG was retrieved by neutralizing with aqueous $\mathrm{NaOH}$. The product so obtained was filtered and washed with water several times followed by drying. The structure of Cht-PEG was characterized using FTIR (Perkin Elmer Version 10.03.05 instrument). A schematic of the synthesis of Cht-PEG is shown in Fig. 1.

Fig. 1 Synthesis of Cht-PEG

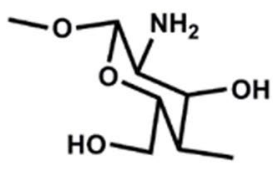

HCHO, PEG

Chitosan

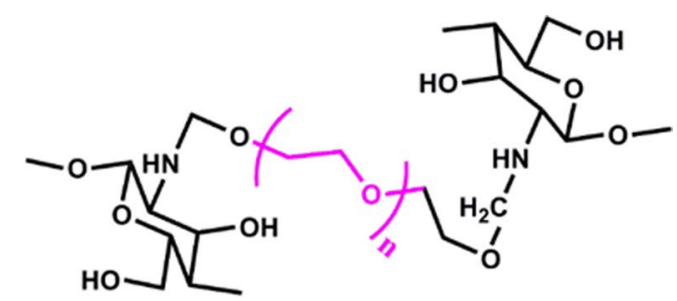

Chitosan-PEG 


\section{Corrosion testing}

\section{Gravimetric measurements}

The mild steel coupons used for the weight loss and electrochemical measurements had following composition (wt $\%$ ) C $0.076 \%$, Si $0.026 \%$, Mn 0.192\%, P $0.012 \%$, Cr 0.050\%, Ni $0.050 \%, \mathrm{Al} 0.023 \%, \mathrm{Cu} 0.135 \%$ and balance $\mathrm{Fe}[9,10$, 26]. The coupons subjected for weight loss study had dimensions of $2.5 \times 2.0 \times 0.025 \mathrm{~cm}$. After abrading the coupons with $\mathrm{SiC}$ paper (grade 600-1200), the samples were rinsed with distilled water, degreased with acetone, dried in hot air, and stored in moisture-free desiccators.

The weight loss studies were carried out following immersion of the mild steel coupons in $1 \mathrm{M}$ sulphamic acid solution in the absence and the presence of varying concentrations of Cht-PEG using the ASTM procedure [27, 28]. After $3 \mathrm{~h}$, the samples were taken out, washed with distilled water and acetone, dried in a moisture free desiccator and again weighed accurately using an analytical balance (precision $\pm 0.1 \mathrm{mg}$ ). The experiments were performed in aerated and unstirred solution at different temperatures.

\section{Electrochemical studies}

The electrochemical corrosion testing was performed using a Gamry Potentiostat/Galvanostat (Model G-300) connected with a personal computer with Echem Analyst 5.0 software package [29-31]. The electrochemical cell consisted of a three-electrode assembly where a mild steel strip with an exposed area of $1 \mathrm{~cm}^{2}$ was used as working electrode, a graphite rod as counter electrode and a saturated calomel electrode (SCE) as reference electrode. Prior to measurements, the working electrode was immersed in the test solution at open circuit potential (OCP) for $30 \mathrm{~min}$ to attain a steady state condition. All the electrochemical experiments were performed at $308 \mathrm{~K}$. The electrochemical impedance spectroscopy (EIS) was carried out by an applying AC signal with an amplitude of $10 \mathrm{mV}$ peak to peak at OCP, in the frequency range of $100 \mathrm{kHz}$ to $0.01 \mathrm{~Hz}$ [32]. The potentiodynamic polarization measurements were carried out by sweeping the electrode potential automatically from -250 to $+250 \mathrm{mV}$ vs. OCP at a scan rate of $0.1 \mathrm{mV} \mathrm{s}^{-1}[29,31]$.

\section{Surface analysis}

The specimens were immersed in $1 \mathrm{M}$ sulphamic acid solution in the absence and presence of optimum concentration (150 $\mathrm{mg} \mathrm{L}^{-1}$ ) of inhibitor Cht-PEG for $3 \mathrm{~h}$ at $308 \mathrm{~K}$. Following the immersion period, the samples were taken out of the test solutions, cleaned with double distilled water and dried. The adsorption of Cht-PEG on the surface of mild steel was studied by performing FTIR in attenuated total reflection (ATR) mode.
The influence of adsorption of inhibitor on mild steel was also studied by recording the surface morphology using scanning electron microscopy (SEM). The SEM images were recorded by a Ziess Evo $50 \mathrm{XVP}$ instrument operating at an accelerating voltage of $20 \mathrm{kV}$.

\section{Theoretical studies}

The quantum chemical calculations were performed on the studied inhibitor using the density functional theory (DFT) method. The DFT calculations were performed using the Becke three-parameter hybrid functional together with the Lee-Yang-Parr correlation functional (B3LYP) and the $6-31+\mathrm{G}(\mathrm{d}, \mathrm{p})$ basis set $[33,34]$. The calculations were performed using Gaussian 09 software [34, 35] for Windows. The frontier molecular orbital (FOM) energies i.e. the energy of the highest occupied molecular orbital $\left(E_{\mathrm{HOMO}}\right)$ and the energy of the lowest unoccupied molecular orbital $\left(E_{\mathrm{LUMO}}\right)$ were evaluated. On the basis of this data, the other parameters were evaluated $[9,10,26]$.

\section{Results and discussion}

\section{Gravimetric measurements}

\section{Effect of inhibitor concentration}

The influence of inhibitor concentration (ranging from 50 to $250 \mathrm{mg} \mathrm{L}^{-1}$ ) on the corrosion inhibition efficiency was studied after $3 \mathrm{~h}$ exposure to $1 \mathrm{M}$ sulphamic acid in the absence and presence of Cht-PEG. A graphical presentation of the obtained results is depicted in Fig. 2a. The corrosion rate $C_{\mathrm{R}}\left(\mathrm{mg} \mathrm{cm}^{-2}\right.$ $\mathrm{h}^{-1}$ ) was computed using Eq. (1) [26, 29, 31]:

$C_{\mathrm{R}}=\frac{W}{A t}$

where, $W$ denotes the average weight loss of mild steel coupon, $A$ is the total area and trepresents the immersion time $(3 \mathrm{~h})$. The corrosion inhibition efficiency ( $\eta \%$; relative decrease in corrosion rate in the presence of a corrosion inhibitor), was calculated using Eq. (2) [25, 29, 31]:

$\eta \%=\frac{C_{\mathrm{R}}-C_{\mathrm{Ri}}}{C_{\mathrm{R}}} \times 100$

where $C_{\mathrm{R}}$ and $C_{\mathrm{Ri}}$ are the corrosion rates in the absence and presence of different concentrations of inhibitor, respectively. The surface coverage $(\theta)$ was calculated using Eq. (3) $[25,29,31]$ :

$\theta=\frac{C_{\mathrm{R}}-C_{\mathrm{Ri}}}{C_{\mathrm{R}}}$ 
Fig. 2 a Variation of the inhibition efficiency $(\eta \%)$ with inhibitor concentration at $308 \mathrm{~K}$; b variation of inhibition efficiency $(\eta \%)$ with solution temperature $(308-338 \mathrm{~K})$ at optimum concentration of inhibitor; $\mathbf{c}$ Arrhenius plots of the corrosion rate $\left(C_{\mathrm{R}}\right)$ of mild steel in $1 \mathrm{M}$ sulphamic acid in the absence and presence of optimum concentration $\left(200 \mathrm{mg} \mathrm{L}^{-1}\right)$ of Cht-PEG
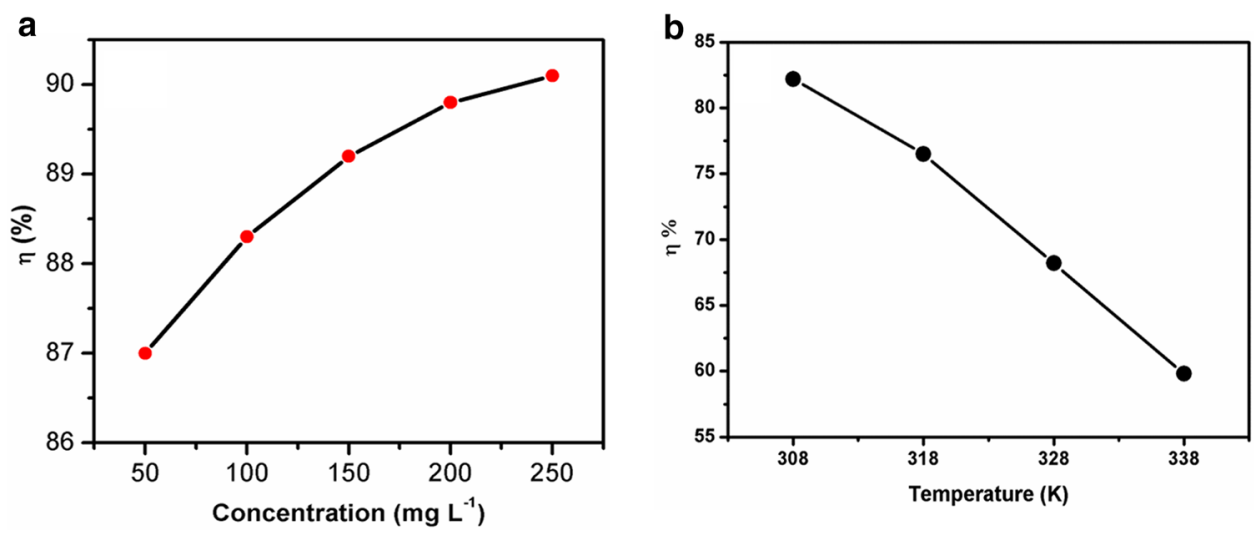

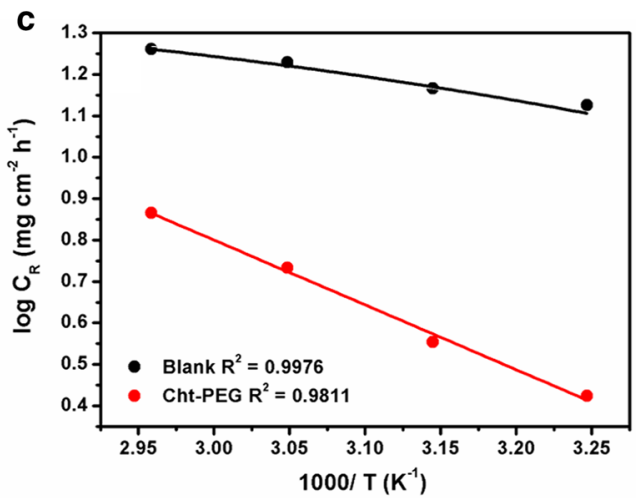

\section{Effect of temperature}

Table 1 Gravimetric parameters obtained for mild steel in $1 \mathrm{M}$ sulphamic acid in the absence and presence of different concentrations of Cht-PEG

\begin{tabular}{lllll}
\hline & $\begin{array}{l}\text { Inhibitor conc. } \\
\left(\mathrm{mg} \mathrm{L}^{-1}\right)\end{array}$ & $\begin{array}{l}C_{\mathrm{R}} \\
\left(\mathrm{mg} \mathrm{cm}^{-2} \mathrm{~h}^{-1}\right)\end{array}$ & $\begin{array}{l}\text { Surface cov- } \\
\text { erage }(\theta)\end{array}$ & $\eta \%$ \\
\hline Blank & 0.0 & 12.27 & - & - \\
Cht-PEG & 50 & 1.59 & 0.8704 & 87.0 \\
& 100 & 1.44 & 0.8832 & 88.3 \\
& 150 & 1.32 & 0.8924 & 89.2 \\
& 200 & 1.25 & 0.8993 & 89.9 \\
& 250 & 1.23 & 0.9092 & 90.2 \\
\hline
\end{tabular}

The weight loss parameters viz. corrosion rate $\left(C_{\mathrm{R}}\right)$, surface coverage $(\theta)$ and the corrosion inhibition efficiency $(\eta \%)$ were calculated and presented in Table 1. The increase in inhibition efficiency with increase in concentration of Cht-PEG suggests that the inhibitor acts by adsorbing at the mild steel surface. The inhibition efficiency reached $89.9 \%$ at a concentration of $200 \mathrm{mg} \mathrm{L}^{-1}$ beyond which no major increase in $\eta \%$ was observed. Therefore, this concentration was selected as the optimum concentration of the inhibitor for further studies.
The influence of temperature on the corrosion inhibition efficiency was studied at the optimum concentration $(200 \mathrm{mg}$ $\mathrm{L}^{-1}$ ) of the inhibitor in the temperature range of 308-338 K. It can be observed from Fig. $2 b$ that the inhibition efficiency decreases with increase in the temperature. A rise in the temperature of the corrosive medium usually accelerates the rates of the corrosion reactions which results in an increased dissolution rate of the metal. An increase in the temperature also leads to an increase in the desorption of the inhibitor molecules from the metal surface which consequently, exposes a greater surface area of the metal sample towards the corrosive attack of the medium and in turns leads to increase in the rate of corrosion [36, 37].

The dependence of corrosion rate on temperature can be elucidated with the Arrhenius equation as given below:

$C_{\mathrm{R}}=A \exp \left(\frac{-E_{\mathrm{a}}}{R T}\right)$

where $E_{\mathrm{a}}$ represents the energy of activation, $T$ is the absolute temperature, $A$ denotes the Arrhenius pre-exponential factor and $R$ is the universal gas constant. A plot between log $C_{\mathrm{R}}$ and $1 / T$ is known as an Arrhenius plot which is a straight line with a slope of $E_{\mathrm{a}} / 2.303 R$ as shown in Fig. 2c. The calculated value of $E_{\mathrm{a}}$ in blank $1 \mathrm{M}$ sulphamic acid was 10.65 
$\mathrm{kJ} \mathrm{mol}^{-1}$ while in the presence of Cht-PEG it was found to be $29.96 \mathrm{~kJ} \mathrm{~mol}^{-1}$. A higher value of $E_{\mathrm{a}}$ in the presence of inhibitor indicates the creation of a barrier for corrosion process, which raises the activation energy and decreases the rate of metallic corrosion [29, 30]. This observation supports the interaction between the inhibitor molecules and the metal surface [38].

\section{Adsorption isotherm}

The adsorption isotherms are used to understand the interaction of inhibitor molecules with metal surfaces. For the adsorption of Cht-PEG over mild steel surface, in the present investigation, several adsorption isotherms were attempted to fit the values of surface coverage $\theta$, among which the Langmuir isotherm provided the best results. The results of other tested isotherms are given in the supplementary information as Fig. S1. The Langmuir isotherm is given by the following equation:

$\theta /(1-\theta)=K_{\mathrm{ads}} C$

where $C$ represents the concentration of the inhibitor and $K_{\text {ads }}$ denotes the equilibrium constant for the adsorption process [38]. The curve in Fig. 3 shows a plot of $C$ vs $\log C / \theta$ with the values of the slope and the regression coefficient close to 1 . The value of $K_{\text {ads }}$ can be calculated from the intercept of the straight line and it was found to be $260.1 \mathrm{~L} \mathrm{~g}^{-1}$. The $K_{\text {ads }}$ is related to the free energy of adsorption $\Delta G_{\text {ads }}^{\circ}$ according to the following equation:

$\Delta G_{\text {ads }}^{\circ}=-R T \ln \left(1000 K_{\text {ads }}\right)$

where $R$ is the universal gas constant, $T$ represents the absolute temperature, and 1000 is the concentration of water in $\mathrm{g} \mathrm{L}^{-1}$. The value of $\Delta G_{\text {ads }}^{\circ}$ for Cht-PEG was computed to be $-31.9 \mathrm{~kJ} \mathrm{~mol}^{-1}$ which suggests that the adsorption of

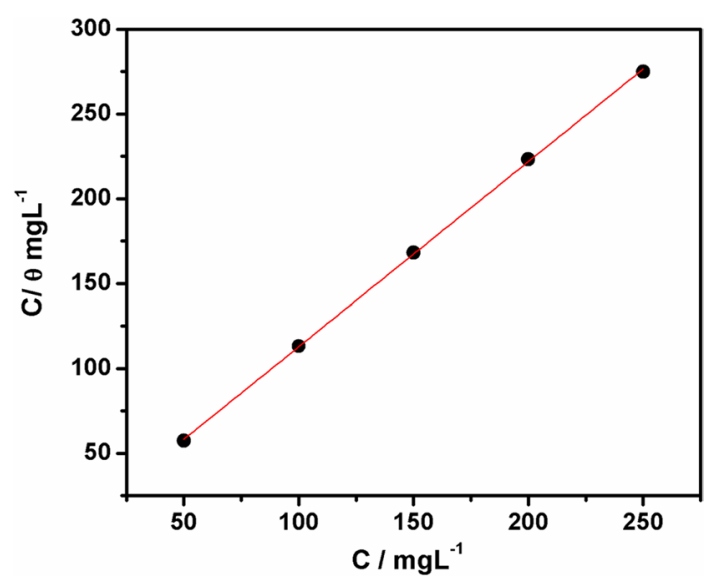

Fig. 3 Langmuir isotherm plot for the adsorption of Cht-PEG on mild steel surface in $1 \mathrm{M}$ sulphamic acid
Cht-PEG follows both physical and chemical modes [29, 31]. The negative sign suggests that the adsorption of ChtPEG on mild steel surface is a spontaneous process.

\section{Electrochemical studies}

\section{Electrochemical Impedance Spectroscopy}

The Nyquist plots of the mild steel electrode [39, 42], obtained in $1 \mathrm{M}$ sulphamic acid solution in the absence and presence of different concentrations of inhibitor are shown in Fig. 4. The curves depict depressed semicircles characteristic of a single time constant which shows a charge transfer control of the process. To correctly simulate the electrochemical process taking place at the metal-electrolyte interface, an equivalent circuit model was used as shown in Fig. 4a. The experimental and fitted curves obtained for mild steel in $1 \mathrm{M}$ sulphamic acid in the presence of varying concentrations of Cht-PEG are shown in Fig. 4c. According to the proposed equivalent circuit, the fitted curves exhibit a good agreement with the experimentally obtained impedance data. Here the solution resistance $\left(R_{\mathrm{s}}\right)$ represents the collective resistance posed by the solution and the electrical connections. For the blank mild steel solution, the polarization resistance $\left(R_{\mathrm{p}}\right)$ contains the charge transfer resistance $\left(R_{\mathrm{ct}}\right)$ and the double layer resistance $\left(R_{\mathrm{d}}\right)$. However, in the presence of the inhibitor, the $R_{\mathrm{p}}$ represents the sum of $R_{\mathrm{ct}}$, the film resistance $\left(R_{\mathrm{f}}\right)$ and the resistance $R_{\mathrm{a}}$ (resistance of all accumulated kinds e.g. inhibitor molecules, corrosion products etc.) at the metal-solution interface [40].

In the present study, the constant phase element (CPE) is used in place of the classical double layer capacitor to take into account the depression in the capacitive semicircle which arises due to surface roughness, impurities, dislocations, grain boundaries, adsorbed inhibitor molecules etc. [41]. The CPE represents a frequency distributed double layer capacitance having phase shift $(n)$. By applying the equivalent circuit, the different EIS parameters are evaluated and are shown in Table 2.

The impedance of the CPE is frequency dependent and can be calculated using Eq. (7) [26]:

$Z_{\mathrm{CPE}}=Y_{0}^{-1}(j \omega)^{-n}$

where $Z_{\mathrm{CPE}}$ represents the impedance of CPE, $Y_{0}$ denotes the magnitude of the CPE(in $\Omega^{-1} \mathrm{~s}^{n} \mathrm{~cm}^{-2}$ ), $\omega$ is the angular frequency given by $\omega=2 \pi f$ (having units in $\operatorname{rad~s}^{-1}$ ), $n$ is an exponent related to the phase shift and has a value in the range of $0<n<1$. The double layer capacitance $C_{d l}$ can be calculated as shown in Eq. (8) [28]:

$C_{d l}=Y_{0}\left(\omega_{\max }\right)^{n-1}$

From the data shown in Table 2, it is clear that the successive addition of increasing concentrations of Cht-PEG to 

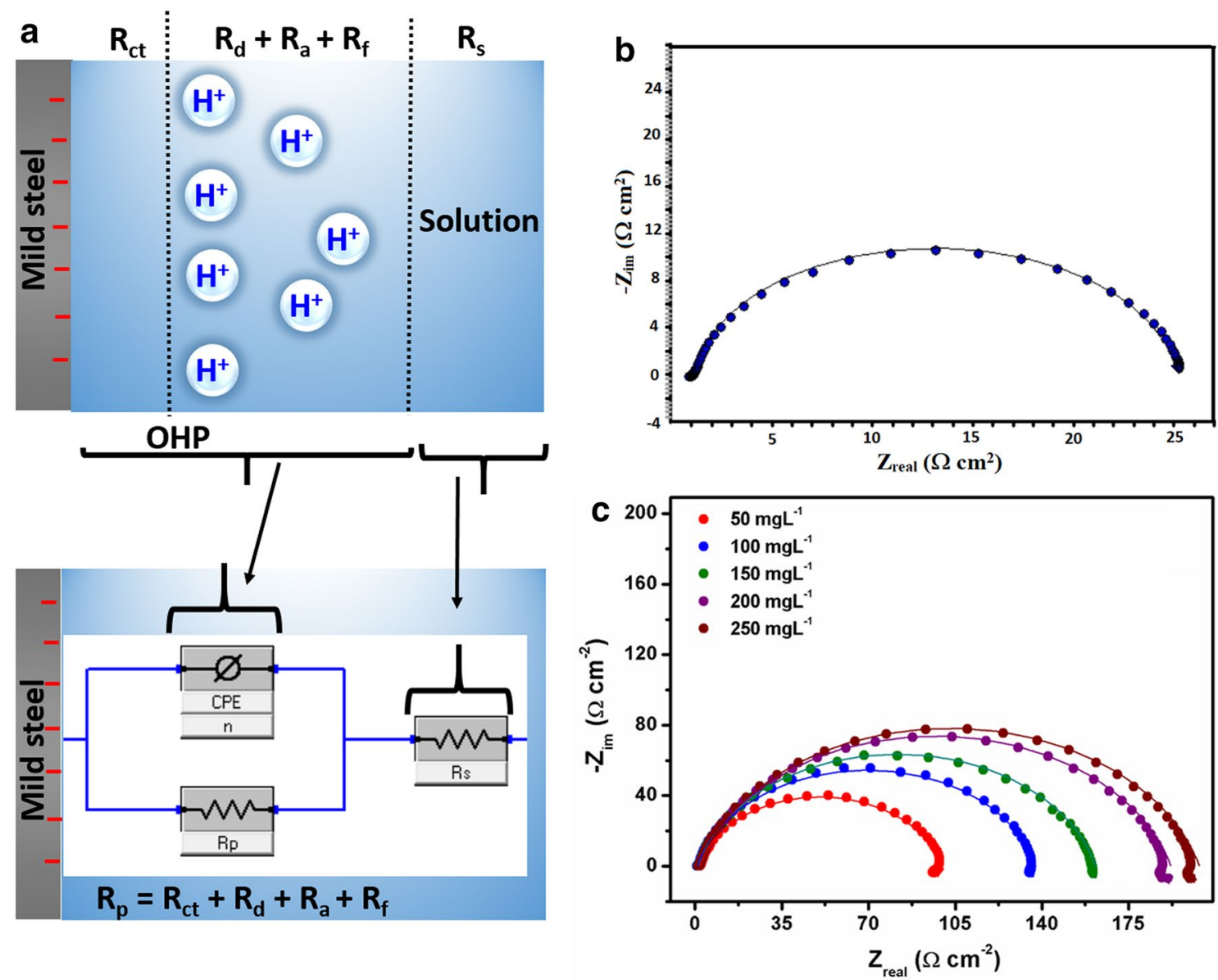

Fig. 4 a Equivalent circuit model used to fit the EIS data; Nyquist plots for mild steel surface in $1 \mathrm{M}$ sulphamic acid in the absence (b) and presence (c) of different concentrations of Cht-PEG at $308 \mathrm{~K}$

Table 2 Electrochemical impedance parameters in the absence and presence of different concentrations of Cht-PEG

\begin{tabular}{lcccccc}
\hline & $\begin{array}{l}\text { Inhibitor conc. } \\
\left(\mathrm{mg} \mathrm{L}^{-1}\right)\end{array}$ & $R_{\mathrm{s}}(\Omega)$ & $R_{\mathrm{p}}\left(\Omega \mathrm{cm}^{2}\right)$ & $n$ & $C_{d l}\left(\mu \mathrm{F} \mathrm{cm}^{-2}\right)$ & $\eta \%$ \\
\hline Blank & & 1.03 & 23.74 & 0.79 & 68.7 & - \\
Cht-PEG & 50 & 1.27 & 93.71 & 0.83 & 57.7 & 76.2 \\
& 100 & 1.52 & 129.1 & 0.86 & 43.9 & 82.1 \\
& 150 & 1.34 & 157.3 & 0.87 & 36.2 & 85.3 \\
& 200 & 1.29 & 192.5 & 0.89 & 28.6 & 88.2 \\
& 250 & 1.31 & 206.5 & 0.88 & 26.6 & 88.5 \\
\hline
\end{tabular}

the corrosive medium results in an increase in the diameter of the Nyquist semicircles. This shows that the inhibitor molecules get adsorbed on the mild steel surface and block the active sites available for corrosion thereby causing an increase in the $R_{\mathrm{p}}$ values which is attributed to a slower corroding system. The inhibition efficiency can be calculated as given by Eq. (9) [42]:

$\eta \%=\frac{R_{\mathrm{p}(\mathrm{inh})}-R_{\mathrm{p}}}{R_{\mathrm{p}(\mathrm{inh})}} \times 100$ where $R_{\mathrm{p}(\mathrm{inh})}$ and $R_{\mathrm{p}}$ represent the polarization resistance obtained in the absence and presence of inhibitor in $1 \mathrm{M}$ sulphamic acid, respectively. The value of inhibition efficiency $(\eta \%)$ increased with increase in the concentration of inhibitor and reached a maximum of $88.2 \%$ at $200 \mathrm{mg} \mathrm{L}^{-1}$. However, the values of $C_{d l}$ show a decrease with increase in the concentration. This observation can be explained using the Helmholtz model which relates the double layer capacitance to the thickness of the protective film formed by the inhibitor molecules $\delta_{\text {org }}$ using following equation [43]: 
$C_{d l}=\frac{\varepsilon_{0} \varepsilon_{r}}{\delta_{\text {org }}}$

where $\varepsilon_{0}$ and $\varepsilon_{r}$ are the permittivity of space and the local dielectric constant respectively. The observed decrease in the $C_{d l}$ values can be attributed to increase in the thickness of $\delta_{\text {org }}$ with increase in concentration of inhibitor. The decrease in $C_{d l}$ values can also be ascribed to a decrease in the local dielectric constant which suggests that the water molecules with a high dielectric constant are being replaced by the inhibitor molecules having a lower dielectric constant.

\section{Potentiodynamic polarization}

Potentiodynamic polarization measurements were performed in $1 \mathrm{M}$ sulphamic acid solution in the absence and presence of varying concentrations of Cht-PEG to evaluate its corrosion inhibition behavior. The representative polarization curves recorded at $308 \mathrm{~K}$ are shown in Fig. 5 and suggest that the corrosion current density decreases after addition of the inhibitor to the test solution. The electrochemical

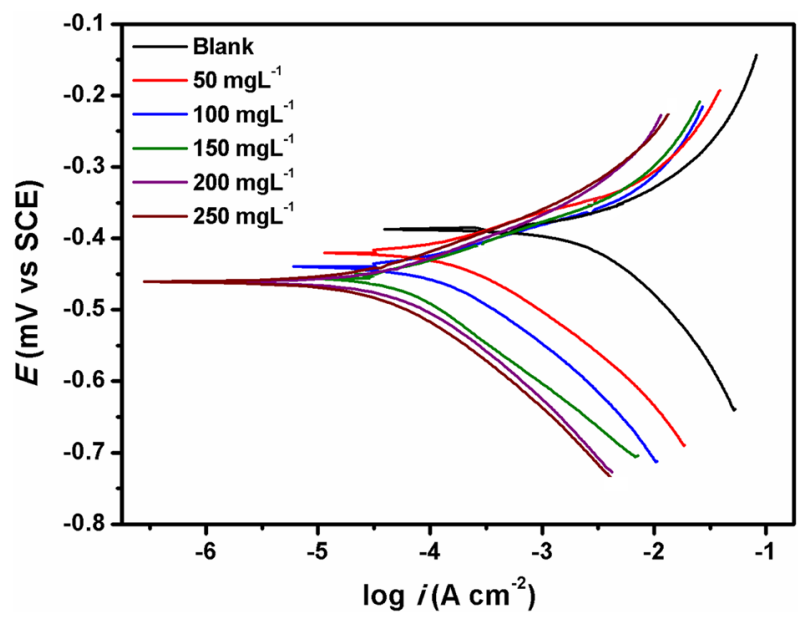

parameters such as the corrosion potential ( $\left.E_{\text {corr }}\right)$, corrosion current density $\left(i_{\text {corr }}\right)$, anodic and cathodic slopes $\left(\beta_{\mathrm{a}}\right.$ and $\beta_{\mathrm{c}}$ ) and corrosion inhibition efficiency $(\eta \%)$ were calculated from the corresponding Tafel curves and are given in Table 3. The corrosion inhibition efficiency can be calculated from $i_{\text {corr }}$ values using following equation [44]:

$\eta \%=\frac{i_{\text {corr }}-i_{\text {corr(inh) }}}{i_{\text {corr }}} \times 100$

where $i_{\text {corr }}$ and $i_{\text {corr(inh) }}$ are the corrosion current densities obtained for mild steel in $1 \mathrm{M}$ sulphamic in the absence and presence of inhibitor.

It can be observed that the successive addition of increasing concentrations of Cht-PEG results in the reduction of anodic metal dissolution and cathodic hydrogen evolution currents thereby decreasing the corrosion rate. From Table 3, it can be observed that the cathodic Tafel slope $\left(\beta_{\mathrm{c}}\right)$ values are significantly greater than that of the anodic Tafel slope $\left(\beta_{\mathrm{a}}\right)$ values. This indicates that the influence of inhibitor on the kinetics of hydrogen evolution is more prominent than that on the Fe dissolution [28, 29, 43]. In addition, it can be seen that the cathodic polarization curves are almost parallel showing no change in the mechanism of hydrogen evolution. This suggests that the hydrogen evolution process follows a charge transfer mechanism [38]. The inhibitor molecules get adsorbed on the mild steel surface and block the active surface sites available for corrosion reaction. Therefore, the available surface area for hydrogen evolution decreases while the actual mechanism of inhibition remains unaffected. The inhibition behavior becomes more pronounced with increase in the concentration of Cht-PEG. At the optimum concentration of $200 \mathrm{mg} \mathrm{L}^{-1}$, the obtained inhibition efficiency was $93.9 \%$ with a little shift in the $E_{\text {corr }}$ values towards cathodic side. These results indicate that the Cht-PEG could be classified as a mixed type corrosion inhibitor showing predominantly cathodic influence.

Fig. 5 Potentiodynamic polarization curves for mild steel in the absence and presence of different concentrations of Cht-PEG

Table 3 Potentiodynamic polarization data for mild steel in the absence and presence of different concentrations of Cht-PEG

\begin{tabular}{llllll}
\hline Inhibitor conc. (ppm) & $\begin{array}{l}E_{\text {corr }} \\
(\mathrm{mV} \text { vs.SCE })\end{array}$ & $\beta_{a}(\mathrm{mV} / \mathrm{dec})$ & $-\beta_{c}(\mathrm{mV} / \mathrm{dec})$ & $I_{\text {corr }}\left(\mu \mathrm{A} / \mathrm{cm}^{2}\right)$ & $\eta \%$ \\
\hline Blank & -391 & 77.9 & 125.4 & 1697 & - \\
Cht-PEG & & & & & \\
50 & -423 & 73.0 & 113.3 & 304.5 & 82.1 \\
100 & -447 & 69.0 & 112.7 & 195.6 & 88.4 \\
150 & -461 & 68.7 & 108.6 & 151.2 & 91.1 \\
200 & -464 & 63.3 & 119.7 & 114.3 & 93.9 \\
250 & -465 & 61.3 & 116.7 & 101.3 & 94.0 \\
\hline
\end{tabular}




\section{FTIR characterization}

The FTIR spectra of Cht and Cht-PEG are shown in Fig. 6a, b respectively. IR $\left(\nu \max \mathrm{cm}^{-1}\right) 3200\left(\mathrm{C}-\mathrm{H}, \mathrm{sp}^{2}\right)$,
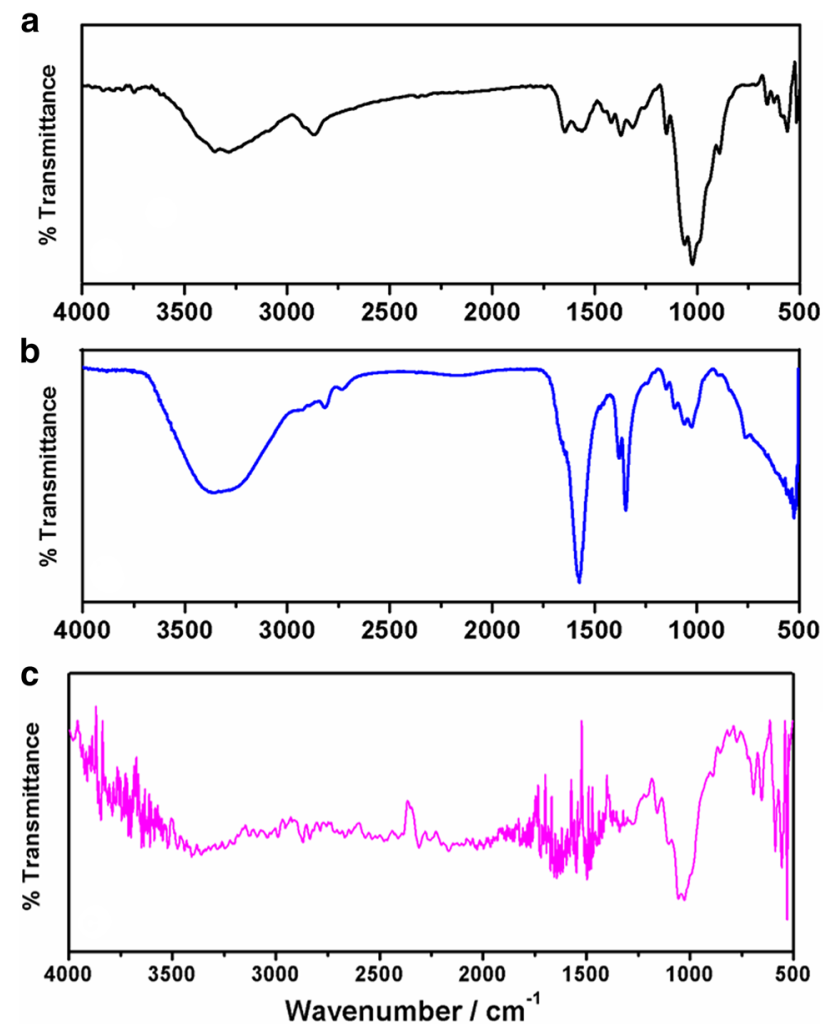

Fig. 6 FTIR spectrum of a Chitosan (Cht); b Cht-PEG and c adsorbed film formed on the mild steel after immersion in $1 \mathrm{M}$ sulphamic acid

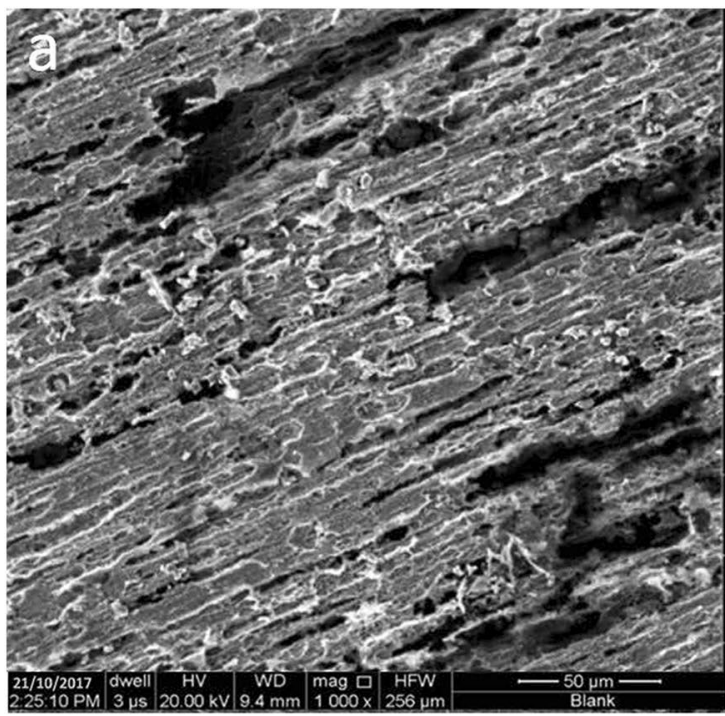

$1682(\mathrm{C}=\mathrm{O}), 1570-1500(\mathrm{C}=\mathrm{C}), 1350(\mathrm{C}-\mathrm{N})$. The ChtPEG shows the characteristic peaks of Cht along with a new peak appearing at $1280 \mathrm{~cm}^{-1}$ due to PEG. The peak at $1580 \mathrm{~cm}^{-1}$ appeared with increased intensity due to the amide II band of the cross-linked Chitosan [25]. The FTIR spectrum of mild steel surface recorded in attenuated total reflection (ATR) mode after immersion in $1 \mathrm{M}$ sulphamic acid solution containing optimum concentration of ChtPEG is shown in Fig. 6c. The spectrum shows the presence of the characteristic peaks from Cht-PEG in the adsorbed film on the metal surface. However, there is a decrease in the intensity and shift in the peak positions which suggests the adsorption of Cht-PEG over mild steel surface [45-48].

\section{Surface morphology}

The scanning electron microscopy (SEM) images of the cleaned and abraded mild steel surface in $1 \mathrm{M}$ sulphamic acid in the absence and the presence of optimum concentration of Cht-PEG are shown in Fig. 7a, b, respectively. The image of the blank mild steel sample (i.e., in the absence of inhibitor) depicts considerable damage and surface inhomogeneity due to corrosive attack of the acid solution. The surface morphology of the mild sample in the presence of optimum concentration of Cht-PEG reveals contrasting characteristics. A considerable improvement in the surface smoothness can be easily observed. This is attributable to the adsorption of Cht-PEG over mild steel surface and the formation of a protective film which isolates the mild steel surface from the surrounding corrosive environment. A schematic representation of adsorption

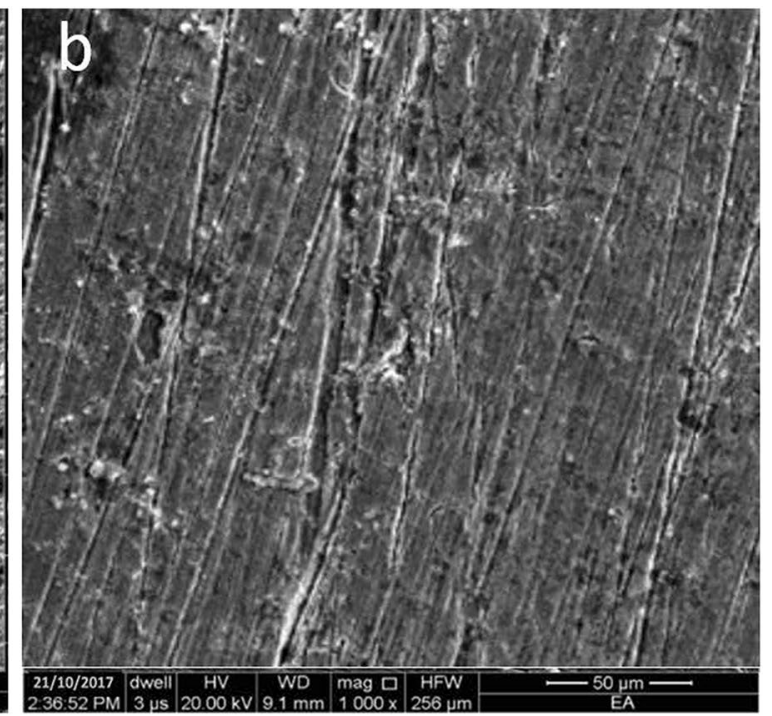

Fig. 7 SEM images of mild steel surface after immersion in a $1 \mathrm{M}$ sulphamic acid; $\mathbf{b}$ in $1 \mathrm{M}$ sulphamic acid containing $200 \mathrm{mg} \mathrm{L}^{-1}$ of Cht-PEG 
Fig. 8 Schematic representation of corrosion and inhibition behavior of the inhibitor (ChtPEG) on mild steel surface

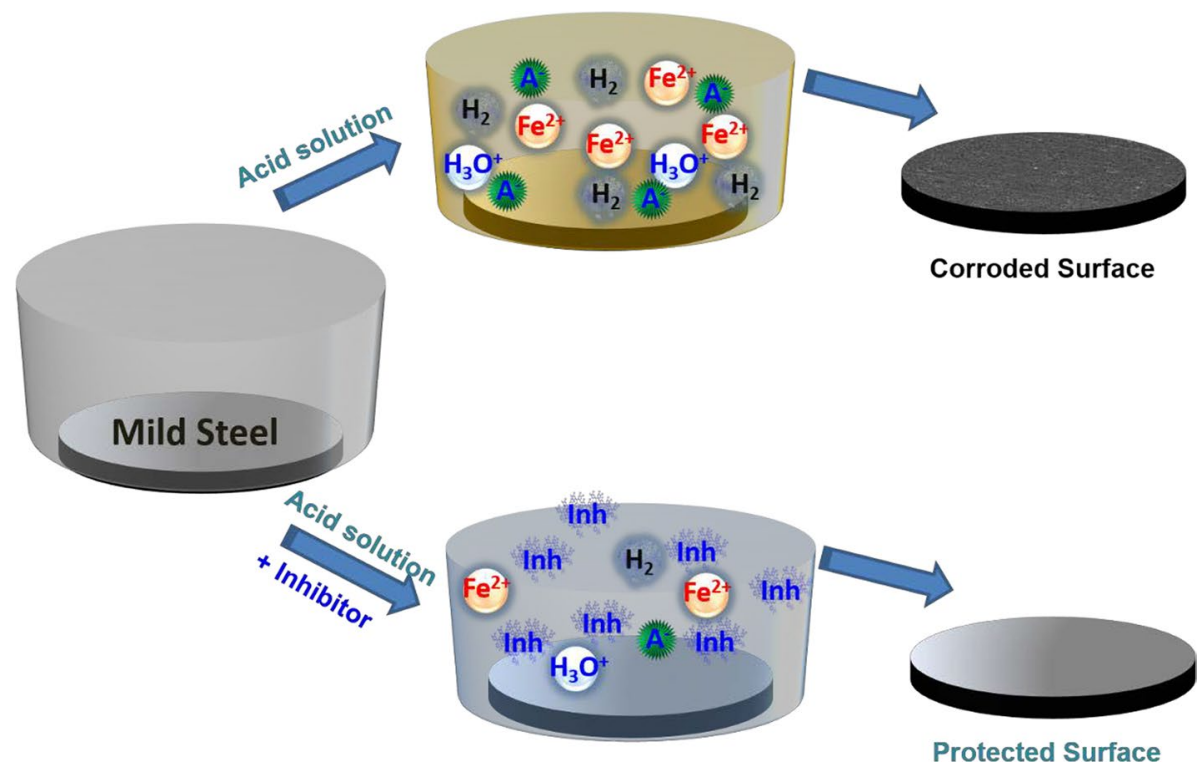

and inhibition behavior of the inhibitor (Cht-PEG) on mild steel surface is shown in Fig. 8.

\section{Computational studies}

\section{Quantum chemical parameters for metal-inhibitor interaction}

Computer-based theoretical methods are frequently employed for predicting structure-activity relationships of pharmaceutically active compounds in the area of corrosion inhibition studies. The density functional theory (DFT) calculations are performed to obtain theoretical parameters such as charge distribution, dipole moment and frontier orbital electron density for designing novel and efficient corrosion inhibitors [49-51]. In the present study, the quantum chemical calculations were performed using density functional theory (DFT) to understand the interaction between inhibitor and the metal surface. In the present study, we performed the calculations on three ethylene glycol units linked between two chitosan units (Cht-EtG) as given in Fig. 9 to understand the effect of functionalization of Cht. The energy of the frontier molecular orbitals (FMO) is important to characterize the electron donation and acceptation tendency of an organic inhibitor. A high value of the energy of the highest occupied molecular orbital ( $E_{\mathrm{HOMO}}$ ) is indicative of the higher tendency of electron donation and a lower value of the energy of the lowest unoccupied molecular orbital $\left(E_{\mathrm{LUMO}}\right)$ presents a tendency towards electron acceptance. According to HSAB principle, the $E_{\mathrm{HOMO}}$ is directly related to ionization potential of a molecule and denotes susceptibility of a molecule towards electrophilic attack. The $E_{\text {LUMO }}$ value is related to electron affinity and characterizes the susceptibility of a molecule towards nucleophilic attack. Frontier molecular orbital theory of chemical reactivity states that the formation of a transition state takes place as a result of an interaction between the frontier orbitals (HOMO and LUMO) of reacting species. Smaller the orbital energy gap between the interacting HOMO and LUMO of molecules, the stronger are the interactions between the molecules of the two reacting species.

In aqueous acidic media, the corrosion inhibitor molecules show the tendency to undergo protonation using the lone pair electrons present on the heteroatoms. Therefore, it is important to understand the reactivity of these protonated species because protonated molecules can also take part in the adsorption process. The preferable site for protonation can be estimated by comparing the proton affinity (PA) values at the different sites [52]. Generally, the heteroatoms of an inhibitor molecule having the most negative Mulliken charges (Table 4) are considered the most probable sites for adsorption. In the present study, the heteroatoms of chitosan i.e., the $\mathrm{O} 33, \mathrm{O} 35$ of the terminal $-\mathrm{OH}$ groups; the $\mathrm{O} 8, \mathrm{O} 31$ of the $-\mathrm{OH}$ groups adjacent to chitosan ring, the $09, \mathrm{O} 29$ of the terminal -O- groups, the $\mathrm{O} 5, \mathrm{O} 25$ of the chitosan ring - $\mathrm{O}-$ groups, the $\mathrm{O} 13$ and O19 of the -O- groups from EG units adjacent to chitosan rings, the -O- group present in the center of EG and the $\mathrm{N} 11, \mathrm{~N} 21$ of the $-\mathrm{NH}$ - groups were considered susceptible for protonation [53]. The proton affinity can be calculated as $[54,55]$ :

$P A=E_{\text {proto }}-\left(E_{\text {non - proto }}+E_{\mathrm{H}^{+}}\right)$

where $E_{\text {non - proto }}$ and $E_{\text {proto }}$ are the energies of the non-protonated and protonated inhibitors, respectively. $E_{\mathrm{H}^{+}}$is the energy of $\mathrm{H}^{+}$ion which can be expressed as [56]:

$E_{\mathrm{H}^{+}}=E_{\left(\mathrm{H}_{3} \mathrm{O}^{+}\right)}-E_{\left(\mathrm{H}_{2} \mathrm{O}\right)}$ 

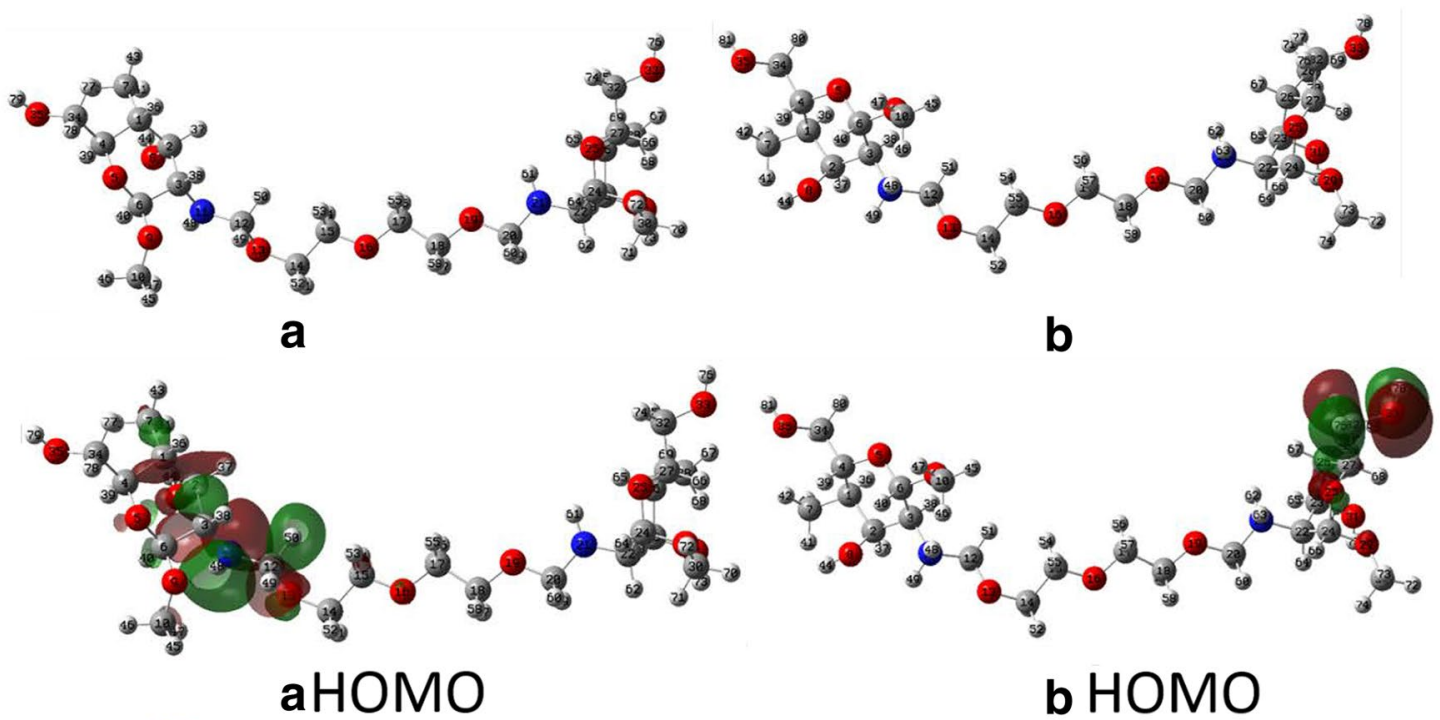

b HOMO
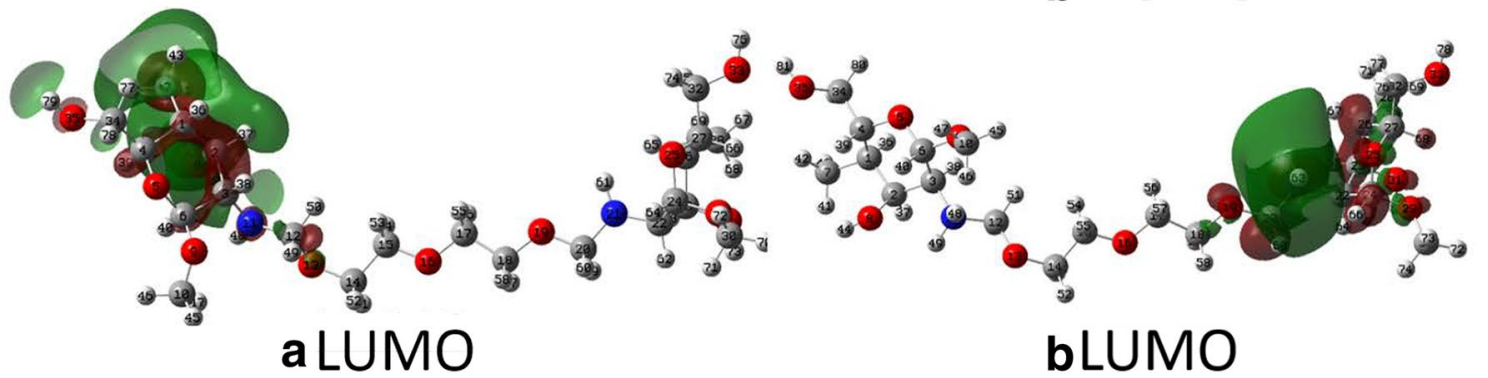

Fig. 9 Optimized structures and frontier orbital electron density distribution (HOMO and LUMO) of a Cht-EG neutral and b Cht-EG protonated

Table 4 Mulliken charges on heteroatoms of Cht-EG

\begin{tabular}{ll}
\hline Heteroatom & Mulliken charge \\
\hline O5 & -0.530875 \\
O8 & -0.564390 \\
O9 & -0.497101 \\
N11 & -0.559576 \\
O13 & -0.511556 \\
O16 & -0.513348 \\
O19 & -0.520670 \\
N21 & -0.558425 \\
O25 & -0.532869 \\
O29 & -0.475880 \\
O31 & -0.545444 \\
O33 & -0.551656 \\
O35 & -0.554711 \\
\hline
\end{tabular}

where, $E_{\left(\mathrm{H}_{2} \mathrm{O}\right)}$ is the total energy of a water molecule and $E_{\left(\mathrm{H}_{3} \mathrm{O}^{+}\right)}$is the total energy of the hydronium ion. The PA values at different positions of protonation are listed in Table 5. It can be observed that the preferred sites for protonation are N11, N21 in the Cht-EG structure [45].
Table 5 Proton affinity values at the different positions of Cht-EG

\begin{tabular}{ll}
\hline Heteroatoms & PA $\left(\mathrm{kcal} \mathrm{mol}^{-1}\right)$ \\
\hline O33, O35 & -1130903.31 \\
O8, O31 & -1130886.07 \\
O9, O29 & -1130866.21 \\
O5, O25 & -1130898.15 \\
O13, O19 & -1130888.4 \\
O16 & -1130734.06 \\
N11, N21 & -1130997.31
\end{tabular}

Following Koopman's theorem, the molecular orbital energies of the FMO can be related to the ionization potential and electron affinity as follows [22, 57-61]:

$-E_{\mathrm{HOMO}}=I$

$-E_{\mathrm{LUMO}}=A$

where $I$ and $A$ represent the ionization potential and the electron affinity, respectively. The electronegativity and hardness can be computed from the above parameters as shown below:

$\chi=\frac{1}{2}(I+A)$ 
$\eta=\frac{1}{2}(I-A)=\frac{1}{\sigma}$

Where, $\chi$ represents the absolute electronegativity, $\eta$ denotes the chemical hardness and $\sigma$ is the global softness which is the reciprocal of hardness. Hardness can also be related to the molecular orbital energy gap $\Delta E$ between HOMO and LUMO. This relation is grounded on the principle of maximum hardness which states that "a molecule arranges itself so as to be as hard as possible" $[52,58,59]$. The electrophilicity index $\omega$ and its inverse, the nucleophilicy $\varepsilon$ can be expressed as:

$\omega=\frac{\chi^{2}}{4 \eta}=\frac{1}{\varepsilon}$

The fraction of electrons transferred $(\Delta N)$ can be given as $[22,49,55,56]$ :

$\Delta N=\frac{\phi_{F e}-\chi_{i n h}}{2 \eta_{i n h}}$

where $\phi_{\mathrm{Fe}}$ represents the work function of the Fe (110) plane having a value of $4.82 \mathrm{eV}$ and the other symbols are as defined above. Accordingly, the calculated quantum chemical parameters for neutral and protonated Cht-EG are listed in Table 6. It can be seen that following protonation, the Cht-EG molecule shows a significant decrease in the $E_{\text {Hомо value compared to that of the protonated molecule }}$ indicating a decrease in the tendency to donate electrons. The $E_{\mathrm{LUMO}}$ value of the protonated inhibitor also shows a significant decrease indicating an increased tendency of electron acceptance compared to the neutral molecule. Further, after protonation, there is a significant rise in the global electronegativity of the Cht-EG molecule combined together with increased value of the electrophilicity index and the decreased value of nucleophilicity. It can also be observed that while $\Delta N$ for neutral inhibitor is $0.46, \Delta N$ for the protonated form is -0.49 . This again suggests that the neutral form of Cht-EG has a tendency to donate the electrons to the metal surface while after protonation the inhibitor molecules exhibit an electron accepting tendency [22, 52, 58]. These parameters further support the increase in electron acceptance tendency compared to that of the electron donation tendency which is exhibited by the neutral Cht-EG molecule.

\section{Molecular electrostatic potential}

The mapping of molecular electrostatic potential (ESP) can allow an observation of the regions of high and low electron density in an organic corrosion inhibitor molecule. This can help determine the possible sites in the inhibitor molecule which are susceptible to undergo adsorption interaction with a metal surface [52, 60, 61]. The ESP mapping of the neutral and protonated Cht-EG are displayed in Fig. 10. The different values of ESP are shown in different colours where the most negative ESP regions are shown in red colour, blue shows the region of the most positive ESP while the green colour shows the regions with zero ESP values [52, 60, 61]. It can be seen that in the neutral inhibitor, the most negative potential (red color) is around the heteroatoms $(\mathrm{O}$ and $\mathrm{N})$. Upon protonation at $\mathrm{N}$ positions, a deep blue coloured region can be observed around the $\mathrm{N}$ atoms showing a deficiency of electrons and the possible centres susceptible for undergoing physical adsorption via electrostatic interaction. These results support the trends observed above in the values of the electrophilicity and the nucleophilicity indices (Table 6).

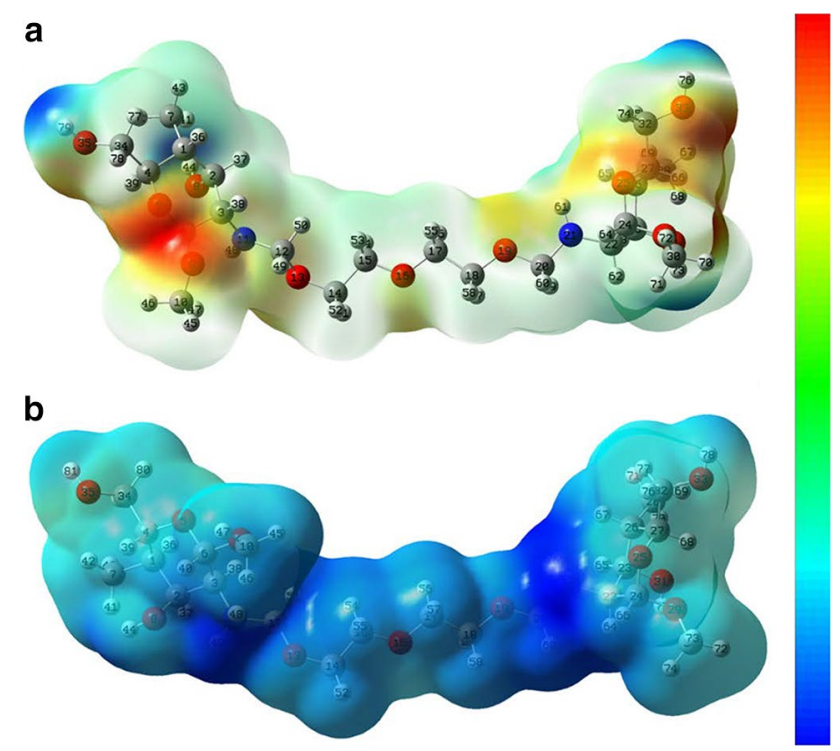

Fig. 10 Molecular electrostatic potential mapping of a neutral and $\mathbf{b}$ protonated Cht-PEG. The bar shows the regions of high (red) and low electron density (blue)
Table 6 Quantum chemical parameters of the neutral and protonated Cht-EG

\begin{tabular}{lrrrrrrrrr}
\hline Cht-EtG & \multicolumn{1}{c}{$E_{\text {Hомо }}$} & \multicolumn{1}{c}{$E_{\text {LUMO }}$} & $\Delta E$ & $\chi$ & $\eta$ & $\sigma$ & $\omega$ & $\varepsilon$ & \multicolumn{1}{c}{$\Delta N$} \\
\hline Neutral & -5.0923 & 1.6699 & 6.76 & 1.71 & 3.38 & 0.29 & 0.22 & 4.62 & 0.46 \\
Protonated & -10.7352 & -4.7457 & 5.99 & 7.74 & 2.99 & 0.33 & 5.00 & 0.19 & -0.49 \\
\hline
\end{tabular}

All energy values are in $\mathrm{eV} ; \sigma$ is in $\mathrm{eV}^{-1}$ 


\section{Explanation of adsorption and inhibition}

The adsorption of an inhibitor at the metal-solution interface is generally assumed to be the first step in the corrosion inhibition process in an aggressive acid solution. Following mechanism is proposed for the interaction of inhibitor over mild steel surface in the acid solution [62].

1. The inhibitor molecule may get protonated in the acidic medium:

$$
[\text { Cht - PEG }]+x \mathrm{H}^{+} \rightleftharpoons[\text { Cht }-\mathrm{PEG}]^{x+}
$$

The protonated inhibitor may get adsorbed directly on the surface by forming electrostatic attraction bridges through previously adsorbed acid anion, or, the protonated inhibitor may adsorb via direct electrostatic attraction with the metal surface. The physically adsorbed protonated Cht-PEG molecules may start to compete with the $\mathrm{H}^{+}$for electrons over the mild steel surface. The protonated inhibitor, after accepting electrons from the metal surface, then returns to the neutral form $[28,30]$.

2. The uncharged or neutral inhibitor molecules may then undergo chemical interaction with the metal surface.

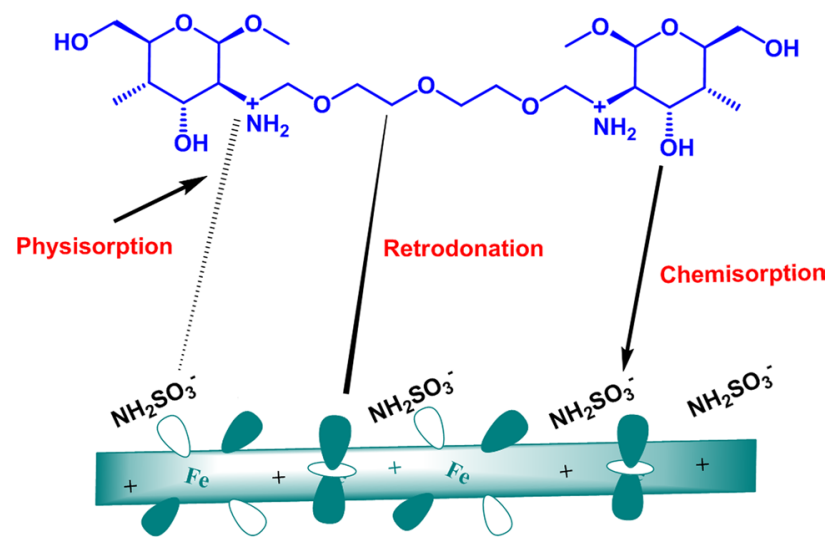

Fig. 11 Schematic of mechanism of adsorption of Cht-PEG on mild steel surface
The presence of heteroatoms $(\mathrm{N}, \mathrm{S}, \mathrm{O}, \mathrm{P})$ in the inhibitor molecule with free lone pair electrons may promote chemical adsorption of the inhibitor over the metal surface.

3. During the corrosion reaction, there can be an accumulation of electrons over the metal surface making it more negatively charged. To relieve this excess negative charge, the electrons from the partially filled d-orbitals of the metal may get transferred to the vacant $\pi$ antibonding orbitals of the inhibitor molecule in a process called retro-donation. This further strengthens the adsorption of inhibitor molecules over the metal surface. A schematic representation of adsorption of inhibitor on mild steel surface is shown in Fig. 11.

A few reports are available on different corrosion inhibitors for sulphamic acid solution for mild steel. A comparison of corrosion inhibition performance of present work with previously tested inhibitors is shown in Table 7 . The present work is the first report on the application of Cht-PEG against corrosion of mild steel in sulphamic acid solution. The obtained experimental results in the present work suggest that the Cht-PEG behaves as a promising inhibitor against mild steel corrosion in $1 \mathrm{M}$ sulphamic acid.

\section{Conclusions}

In the present study, polyethylene glycol (PEG) crosslinked Chitosan (CHt-PEG) was used as corrosion inhibitor for mild steel in $1 \mathrm{M}$ sulphamic acid solution. Following major conclusions were drawn out of the investigation:

1. Polyethylene glycol (PEG) cross-linked Chitosan (ChtPEG) exhibited $93.9 \%$ inhibition efficiency at 200 $\mathrm{mg} \mathrm{L}^{-1}$ concentration against the corrosion of mild steel in $1 \mathrm{M}$ sulphamic acid solution.
Table 7 A comparison of the corrosion inhibition behaviour of Cht-PEG with other inhibitors for sulphamic acid

\begin{tabular}{lllll}
\hline Inhibitor & Metal surface & $\begin{array}{l}\text { Sulphamic acid con- } \\
\text { centration }\end{array}$ & $\begin{array}{l}\text { Inhibition effi- } \\
\text { ciency }(\eta \%)\end{array}$ & References \\
\hline$N$-acetylcysteine & Mild steel & $5 \%$ & 97.4 & {$[2]$} \\
Cysteine & Mild steel & $5 \%$ & 96.7 & {$[2]$} \\
$S$-benzylcysteine & Mild steel & $5 \%$ & 90.7 & {$[2]$} \\
Cystine & Mild steel & $5 \%$ & 93.7 & {$[2]$} \\
Methionine & Mild steel & $5 \%$ & 95.9 & {$[2]$} \\
Chitosan & Mild steel & $1 \mathrm{M}$ & 72.38 & {$[11]$} \\
Chitosan + KI & Mild steel & $1 \mathrm{M}$ & 91.68 & {$[11]$} \\
Cht-PEG & Mild steel & $1 \mathrm{M}$ & 93.9 & Present work \\
\hline
\end{tabular}


2. The corrosion inhibition efficiency showed an increase with increase in the concentration of inhibitor. The adsorption of Cht-PEG on the mild steel surface followed Langmuir isotherm and exhibited a mixed mode of adsorption.

3. EIS study showed an increase in the polarization resistance with increase in concentration thereby supporting the formation of a protective film.

4. Polarization study revealed that the tested inhibitor suppresses both anodic and cathodic processes while exhibiting a cathodic predominance.

5. The results of quantum chemical calculations carried out on neutral and protonated inhibitor supported the experimental results and provided evidence for metalinhibitor interaction.

Acknowledgements Dr. Dheeraj Singh Chauhan gratefully acknowledges King Fahd University of Petroleum and Minerals for Post-doctoral research fellowship. Prof. M.A. Quraishi gratefully acknowledges the financial assistance from DIH Project, IIT (BHU).

Open Access This article is distributed under the terms of the Creative Commons Attribution 4.0 International License (http://creativeco mmons.org/licenses/by/4.0/), which permits unrestricted use, distribution, and reproduction in any medium, provided you give appropriate credit to the original author(s) and the source, provide a link to the Creative Commons license, and indicate if changes were made.

\section{References}

1. Motamedi M, Tehrani-Bagha AR, Mahdavian M (2011) A comparative study on the electrochemical behavior of mild steel in sulfamic acid solution in the presence of monomeric and gemini surfactants. Electrochim Acta 58:488-496. https://doi.org/10.1016/j. electacta.2011.09.079

2. Morad MS (2008) Corrosion inhibition of mild steel in sulfamic acid solution by S-containing amino acids. J Appl Electrochem 38:1509-1518. https://doi.org/10.1007/s10800-008-9595-2

3. Hermas AA, Morad MS (2008) A comparative study on the corrosion behaviour of 304 austenitic stainless steel in sulfamic and sulfuric acid solutions. Corros Sci 50:2710-2717. https://doi. org/10.1016/j.corsci.2008.06.029

4. Motamedi M, Tehrani-Bagha AR, Mahdavian M (2013) Effect of aging time on corrosion inhibition of cationic surfactant on mild steel in sulfamic acid cleaning solution. Corros Sci 70:46-54. https://doi.org/10.1016/j.corsci.2013.01.007

5. Cai L, Fu Q, Shi R, Tang Y, Long Y-T, He X-P, Jin Y, Liu G, Chen G-R, Chen K (2013) 'Pungent' copper surface resists acid corrosion in strong $\mathrm{HCl}$ solutions. Ind Eng Chem Res 53(1):64-69

6. Deng Q, He X-P, Shi H-W, Chen B-Q, Liu G, Tang Y, Long Y-T, Chen G-R, Chen K (2012) Concise CuI-catalyzed azide-alkyne 1, 3-dipolar cycloaddition reaction ligation remarkably enhances the corrosion inhibitive potency of natural amino acids for mild steel in HCl. Ind Eng Chem Res 51(21):7160-7169

7. Deng Q, Shi H-W, Ding N-N, Chen B-Q, He X-P, Liu G, Tang Y, Long Y-T, Chen G-R (2012) Novel triazolyl bis-amino acid derivatives readily synthesized via click chemistry as potential corrosion inhibitors for mild steel in HCl. Corros Sci 57:220-227
8. Deng Q, Ding N-N, Wei X-L, Cai L, He X-P, Long Y-T, Chen G-R, Chen K (2012) Identification of diverse 1, 2, 3-triazoleconnected benzyl glycoside-serine/threonine conjugates as potent corrosion inhibitors for mild steel in $\mathrm{HCl}$. Corros Sci 64:64-73

9. Singh P, Ebenso EE, Olasunkanmi LO, Obot IB, Quraishi MA (2016) Electrochemical, theoretical, and surface morphological studies of corrosion inhibition effect of green naphthyridine derivatives on mild steel in hydrochloric acid. J Phys Chem C 120:3408-3419. https://doi.org/10.1021/acs.jpcc.5b11901

10. Verma C, Olasunkanmi LO, Ebenso EE, Quraishi MA, Obot IB (2016) Adsorption behavior of glucosamine-based, pyrimidinefused heterocycles as green corrosion inhibitors for mild steel: experimental and theoretical studies. J Phys Chem C 120:1159811611. https://doi.org/10.1021/acs.jpcc.6b04429

11. Ashassi-Sorkhabi H, Ghalebsaz-Jeddi N (2005) Inhibition effect of polyethylene glycol on the corrosion of carbon steel in sulphuric acid. Mater Chem Phys 92:480-486. https://doi. org/10.1016/j.matchemphys.2005.01.059

12. El-Haddad MN (2013) Chitosan as a green inhibitor for copper corrosion in acidic medium. Int J Biol Macromol 55:142-149. https://doi.org/10.1016/j.ijbiomac.2012.12.044

13. Umoren SA, Banera MJ, Alonso-Garcia T, Gervasi CA, Mirífico MV (2013) Inhibition of mild steel corrosion in $\mathrm{HCl}$ solution using chitosan. Cellulose 20:2529-2545. https://doi. org/10.1007/s10570-013-0021-5

14. Umoren SA, Eduok UM (2016) Application of carbohydrate polymers as corrosion inhibitors for metal substrates in different media: a review. Carbohydr Polym 140:314-341. https://doi. org/10.1016/j.carbpol.2015.12.038

15. Gupta NK, Joshi PG, Srivastava V, Quraishi MA (2017) Chitosan: a macromolecule as green corrosion inhibitor for mild steel in sulfamic acid useful for sugar industry. Int J Biol Macromol

16. Mobin M, Rizvi M (2017) Polysaccharide from Plantago as a green corrosion inhibitor for carbon steel in $1 \mathrm{M} \mathrm{HCl}$ solution. Carbohydr Polym 160:172-183

17. Umoren SA, Ogbobe O, Okafor PC, Ebenso EE (2007) Polyethylene glycol and polyvinyl alcohol as corrosion inhibitors for aluminium in acidic medium. J Appl Polym Sci 105:3363-3370

18. Umoren SA, Obot IB, Madhankumar A, Gasem ZM (2015) Performance evaluation of pectin as ecofriendly corrosion inhibitor for X60 pipeline steel in acid medium: experimental and theoretical approaches. Carbohydr Polym 124:280-291

19. Hassani Najafabadi A, Abdouss M, Faghihi S (2014) Synthesis and evaluation of PEG-O-chitosan nanoparticles for delivery of poor water soluble drugs: Ibuprofen. Mater Sci Eng C 41:91-99. https://doi.org/10.1016/j.msec.2014.04.035

20. Zhang XG, Teng DY, Wu ZM, Wang X, Wang Z, Yu DM, Li CX (2008) PEG-grafted chitosan nanoparticles as an injectable carrier for sustained protein release. J Mater Sci Mater Med 19:35253533. https://doi.org/10.1007/s10856-008-3500-8

21. Bhattarai N, Ramay HR, Gunn J, Matsen FA, Zhang M (2005) PEG-grafted chitosan as an injectable thermosensitive hydrogel for sustained protein release. J Control Release 103:609-624

22. Chauhan DS, Ansari KR, Sorour AA, Quraishi MA, Lgaz H, Salghi R (2018) Thiosemicarbazide and thiocarbohydrazide functionalized chitosan as ecofriendly corrosion inhibitors for carbon steel in hydrochloric acid solution. Int J Biol Macromol 107:1747-1757

23. Haque J, Srivastava V, Chauhan DS, Lgaz H, Quraishi MA (2018) Microwave-induced synthesis of chitosan schiff bases and their application as novel and green corrosion inhibitors: experimental and theoretical approach. ACS Omega 3(5):5654-5668

24. Prakash N, Vendan SA (2016) Biodegradable polymer based ternary blends for removal oftrace metals from simulated industrial wastewater. Int J Biol Macromol 83:198-208 
25. Kulkarni AR, Hukkeri VI, Sung H, Liang H (2005) A novel method for the synthesis of the PEG-crosslinked Chitosan with a pH-independent swelling behavior. Macromol Biosci 5:925-928

26. Ansari KR, Quraishi MA, Singh A, Ramkumar S, Obote IB (2016) Corrosion inhibition of $\mathrm{N} 80$ steel in $15 \% \mathrm{HCl}$ by pyrazolone derivatives: electrochemical, surface and quantum chemical studies. RSC Adv 6:24130-24141. https://doi.org/10.1039/ C5RA25441H

27. ASTM International (1999) Standard practice for preparing, cleaning, and evaluating corrosion test. Significance 90:1-9. https://doi. org/10.1520/G0001-03R11.2

28. Baboian R, SWD Jr, Hack HP, Hibner EL, Scully JR (2009) Corrosion tests and standards: application and interpretation, 2nd edn, pp 1-886. https://doi.org/10.1520/mnl20-2nd-eb

29. Ansari KR, Quraishi MA, Singh A (2015) Isatin derivatives as a non-toxic corrosion inhibitor for mild steel in $20 \% \mathrm{H}_{2} \mathrm{SO}_{4}$. Corros Sci 95:62-70. https://doi.org/10.1016/j.corsci.2015.02.010

30. Ansari KR, Quraishi MA, Singh A (2015) Corrosion inhibition of mild steel in hydrochloric acid by some pyridine derivatives: an experimental and quantum chemical study. J Ind Eng Chem 25:89-98. https://doi.org/10.1016/j.jiec.2014.10.017

31. Ansari KR, Quraishi MA, Singh A (2014) Schiff's base of pyridyl substituted triazoles as new and effective corrosion inhibitors for mild steel in hydrochloric acid solution. Corros Sci 79:5-15. https://doi.org/10.1016/j.corsci.2013.10.009

32. Yadav DK, Chauhan DS, Ahamad I, Quraishi MA (2013) Electrochemical behavior of steel/acid interface: adsorption and inhibition effect of oligomeric aniline. RSC Adv 3:632-646. https://doi.org/10.1039/C2RA21697C

33. 1988-038 PRA Becke-DFT.pdf, (n.d.)

34. Lee C, Yang W, Parr RG (1988) Development of the Colle-Salvetti correlation-energy formula into a functional of the electron density. Phys Rev B 37:785-789. https://doi.org/10.1103/PhysR evB.37.785

35. Frisch M, Trucks GW, Schlegel HB, Scuseria GE, Robb MA, Cheeseman JR, Scalmani G, Barone V, Mennucci B, Petersson GA (2009) Gaussian 09, revision a. 02, gaussian, Inc., Wallingford, CT. 200

36. Yadav DK, Maiti B, Quraishi M (2010) Electrochemical and quantum chemical studies of 3, 4-dihydropyrimidin-2 (1H)-ones as corrosion inhibitors for mild steel in hydrochloric acid solution. Corros Sci 52(11):3586-3598

37. Yadav DK, Quraishi M, Maiti B (2012) Inhibition effect of some benzylidenes on mild steel in $1 \mathrm{M} \mathrm{HCl}$ : an experimental and theoretical correlation. Corros Sci 55:254-266

38. Khadiri A, Saddik R, Bekkouche K, Aouniti A, Hammouti B, Benchat N, Bouachrine M, Solmaz R (2016) Gravimetric, electrochemical and quantum chemical studies of some pyridazine derivatives as corrosion inhibitors for mild steel in $1 \mathrm{M}$ $\mathrm{HCl}$ solution. J Taiwan Inst Chem Eng 58:552-564. https://doi. org/10.1016/j.jtice.2015.06.031

39. El-Hajjaji F, Messali M, Aljuhani A, Aouad MR, Hammouti B, Belghiti ME, Chauhan DS, Quraishi MA (2018) Pyridaziniumbased ionic liquids as novel and green corrosion inhibitors of carbon steel in acid medium: electrochemical and molecular dynamics simulation studies. J Mol Liq 249:997-1008

40. Solmaz R, Kardaş G, Çulha M, Yazici B, Erbil M (2008) Investigation of adsorption and inhibitive effect of 2-mercaptothiazoline on corrosion of mild steel in hydrochloric acid media. Electrochim Acta 53:5941-5952. https://doi.org/10.1016/j.elect acta.2008.03.055

41. Popova A, Christov M (2006) Evaluation of impedance measurements on mild steel corrosion in acid media in the presence of heterocyclic compounds. Corros Sci 48:3208-3221. https:// doi.org/10.1016/j.corsci.2005.11.001
42. Singh P, Chauhan DS, Srivastava K, Srivastava V, Quraishi MA (2017) Expired atorvastatin drug as corrosion inhibitor for mild steel in hydrochloric acid solution. Int J Ind Chem 8:363-372

43. Özcan M, Dehri I, Erbil M (2004) Organic sulphur-containing compounds as corrosion inhibitors for mild steel in acidic media: correlation between inhibition efficiency and chemical structure. Appl Surf Sci 236:155-164

44. Ansari KR, Quraishi MA (2014) Bis-Schiff bases of isatin as new and environmentally benign corrosion inhibitor for mild steel. J Ind Eng Chem 20:2819-2829. https://doi.org/10.1016/j. jiec.2013.11.014

45. Muralisankar M, Sreedharan R, Sujith S, Bhuvanesh NSP, Sreekanth A (2017) $N(1)$-pentyl isatin- $N(4)$-methyl- $N(4)$-phenyl thiosemicarbazone (PITSc) as a corrosion inhibitor on mild steel in HCl. J Alloys Compd 695:171-182. https://doi.org/10.1016/j. jallcom.2016.10.173

46. Chong AL, Mardel JI, MacFarlane DR, Forsyth M, Somers AE (2016) Synergistic corrosion inhibition of mild steel in aqueous chloride solutions by an imidazolinium carboxylate salt. ACS Sustain Chem Eng 4:1746-1755. https://doi.org/10.1021/acssu schemeng.5b01725

47. Lalitha A, Ramesh S, Rajeswari S (2005) Surface protection of copper in acid medium by azoles and surfactants. Electrochim Acta 51:47-55. https://doi.org/10.1016/j.electacta.2005.04.003

48. Bahrami MJ, Hosseini SMA, Pilvar P (2010) Experimental and theoretical investigation of organic compounds as inhibitors for mild steel corrosion in sulfuric acid medium. Corros Sci 52:2793-2803. https://doi.org/10.1016/j.corsci.2010.04.024

49. Geerlings P, De Proft F, Langenaeker W (2010) Conceptual density functional theory. Chem Rev 9:1793-1873. https://doi. org/10.1021/cr990029p

50. Gece G (2008) The use of quantum chemical methods in corrosion inhibitor studies. Corros Sci 50:2981-2992. https://doi. org/10.1016/j.corsci.2008.08.043

51. Obot IB, Macdonald DD, Gasem ZM (2015) Density functional theory (DFT) as a powerful tool for designing new organic corrosion inhibitors: Part 1: an overview. Corros Sci 99:1-30. https ://doi.org/10.1016/j.corsci.2015.01.037

52. Dohare P, Chauhan D, Sorour A, Quraishi M (2017) DFT and experimental studies on the inhibition potentials of expired Tramadol drug on mild steel corrosion in hydrochloric acid. Mater Discov 9:30-41

53. Ansari K, Quraishi M, Singh A, Ramkumar S, Obote IB (2016) Corrosion inhibition of $\mathrm{N} 80$ steel in $15 \% \mathrm{HCl}$ by pyrazolone derivatives: electrochemical, surface and quantum chemical studies. RSC Adv. 6(29):24130-24141

54. Kaya S, Guo L, Kaya C, Tüzün B, Obot I, Touir R, Islam N (2016) Quantum chemical and molecular dynamic simulation studies for the prediction of inhibition efficiencies of some piperidine derivatives on the corrosion of iron. J Taiwan Inst Chem Eng 65:522-529

55. Obot IB, Ebenso EE, Kabanda MM (2013) Metronidazole as environmentally safe corrosion inhibitor for mild steel in 0.5 $\mathrm{M} \mathrm{HCl}$ : experimental and theoretical investigation. J Environ Chem Eng 1(3):431-439

56. Chauhan DS, Ansari K, Sorour A, Quraishi M, Lgaz H, Salghi R (2017) Thiosemicarbazide and thiocarbohydrazide functionalized chitosan as ecofriendly corrosion inhibitors for carbon steel in hydrochloric acid solution. Int J Biol Macromol

57. Dohare P, Chauhan DS, Hammouti B, Quraishi MA (2017) Experimental and DFT investigation on the corrosion inhibition behavior of expired drug lumerax on mild steel in hydrochloric acid anal. Bioanal Electrochem 9:762

58. Geerlings P, De Proft F, Langenaeker W (2003) Conceptual density functional theory. Chem Rev 103(5):1793-1874 
59. Obot IB, Macdonald DD, Gasem ZM (2015) Density functional theory (DFT) as a powerful tool for designing new organic corrosion inhibitors. Part 1: an overview. Corros. Sci. 99:1-30

60. Haque J, Ansari K, Srivastava V, Quraishi M, Obot I (2017) Pyrimidine derivatives as novel acidizing corrosion inhibitors for N80 steel useful for petroleum industry: a combined experimental and theoretical approach. J Ind Eng Chem 49:176-188

61. Haque J, Srivastava V, Verma C, Quraishi M (2017) Experimental and quantum chemical analysis of 2-amino-3-((4- $((S)-$ 2-amino-2-carboxyethyl)-1H-imidazol-2-yl) thio) propionic acid as new and green corrosion inhibitor for mild steel in $1 \mathrm{M}$ hydrochloric acid solution. J Mol Liq 225:848-855

\section{Affiliations}

\section{S. Chauhan ${ }^{1}$ - V. Srivastava ${ }^{2}$.P. G. Joshi ${ }^{2}$ M. A. Quraishi ${ }^{1}$}

\author{
D. S. Chauhan \\ dheeraj.chauhan@kfupm.edu.sa \\ $\triangle$ M. A. Quraishi \\ mumtaz.quraishi@kfupm.edu.sa
}

62. Banerjee G, Malhotra SN (1992) Contribution to adsorption of aromatic amines on mild steel surface from $\mathrm{HCl}$ solutions by impedance, UV, and Raman spectroscopy. Corrosion 48:10-15. https://doi.org/10.5006/1.3315912

Publisher's Note Springer Nature remains neutral with regard to jurisdictional claims in published maps and institutional affiliations.
1 Center of Research Excellence in Corrosion, Research Institute, King Fahd University of Petroleum and Minerals, Dhahran 31261, Saudi Arabia

2 Department of Chemistry, Indian Institute of Technology (Banaras Hindu University), Varanasi 221005, India 